\title{
Trends in Suicide Mortality in South Africa, 1997 to 2016
}

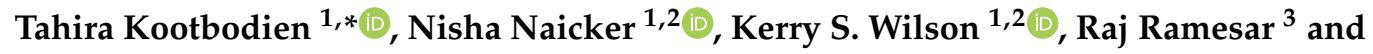 \\ Leslie London 4 \\ 1 National Institute for Occupational Health, National Health Laboratory Services, Constitution Hill, \\ Johannesburg 2001, South Africa; nishan@nioh.ac.za (N.N.); kerryw@nioh.ac.za (K.S.W.) \\ 2 School of Public Health, Faculty of Health Sciences, University of Witwatersrand, Johannesburg 2193, \\ South Africa \\ 3 Division of Human Genetics, University of Cape Town, Cape Town 7925, South Africa; raj.ramesar@uct.ac.za \\ 4 School of Public Health and Family Medicine, University of Cape Town, Cape Town 7925, South Africa; \\ leslie.london@uct.ac.za \\ * Correspondence: tahirak@nioh.ac.za
}

Received: 5 February 2020; Accepted: 9 March 2020; Published: 12 March 2020

\begin{abstract}
Suicide rates worldwide are declining; however, less is known about the patterns and trends in mortality from suicide in sub-Saharan Africa. This study evaluates trends in suicide rates and years of potential life lost from death registration data in South Africa from 1997 to 2016. Suicide (X60-X84 and Y87) was coded using the 10th Revision of the International Classification of Diseases (ICD-10). Changes in mortality rate trends were analysed using joinpoint regression analysis. The 20-year study examines 8573 suicides in South Africa, comprising $0.1 \%$ of all deaths involving persons 15 years and older. Rates of suicide per 100,000 population were 2.07 in men and 0.49 in women. Joinpoint regression analyses showed that, while the overall mortality rate for male suicides remained stable, mortality rates due to hanging and poisoning increased by $3.9 \%$ and $3.5 \%$ per year, respectively. Female suicide mortality rates increased by $12.6 \%$ from 1997 to 2004 before stabilising; while rates due to hanging increased by $3.0 \%$ per year. The average annual YPLL due to suicide was 9559 in men and 2612 in women. The results show that suicide contributes substantially to premature death and demonstrates the need for targeted interventions, especially among young men in South Africa.
\end{abstract}

Keywords: suicide mortality; joinpoint regression analysis; trends; years of potential life lost; suicide rates

\section{Introduction}

Suicide contributed approximately 817,000 deaths to global mortality in 2016, accounting for $1.5 \%$ of the total deaths in the world [1]. Findings from the Global Burden of Disease Study 2016 showed that, while an increase in the absolute number of suicide deaths worldwide was observed from 1990 to 2016, there was a significant decrease in the global age-standardised suicide mortality rate (ASMR) by a third, from 16.6 to 11.2 deaths per 100,000 population [1]. It is estimated that approximately $80 \%$ of all suicides occur in low- and middle-income countries [2]. In 2016, southern sub-Saharan Africa had the third-highest regional suicide mortality rate (ASMR 16.3 per 100,000) in the world, with approximately 11,000 suicide deaths contributing to the burden of disease [1].

Suicide is a complex behaviour consisting of an interplay between many risks and protective factors impacting at individual, family, community and societal levels [3]. Suicide varies with sex and age-groups across different countries and regions. Suicide mortality is higher among men than women in general, as women report more suicidal thoughts and men are more likely to die by suicide [4]. 
Suicide rates in Africa are at least three times higher in men than women [5] and approximately five times higher in South African men compared to women [6], although the distribution varies across population groups and cities [7]. Globally, suicide mortality is higher among younger adults and adults later in life, whereas in sub-Saharan Africa, the suicide mortality rate increases with age [8]. The choice of suicide method varies by socioeconomic levels of countries [9], social, religious and cultural beliefs, and availability and access to a particular method [10]. Variability on the prevalent methods of suicide (hanging, use of firearms or poisoning) has been reported across African countries [5], with hanging and poisoning reported as the most common methods used in South Africa [11,12].

Monitoring of suicide mortality data can be used as a surveillance tool to identify the mental health needs of a population. Moreover, it can inform prevention efforts by monitoring progress in the implementation of programmes to reduce the morbidity and mortality associated with mental illness [13]. However, for monitoring to be optimal, mortality data needs to be accurate, complete and timely [14]. Subsequently, efforts have been made to improve the quality of mortality data in South Africa [15]. Within this context, this study aims to analyse trends in suicide mortality and patterns in the choice of suicide methods to identify populations at risk in South Africa.

\section{Materials and Methods}

\subsection{Data Sources and Data Management}

We obtained the underlying cause of death data based on death certificate information reported to Statistics South Africa from the Department of Home Affairs for each year from 1997 to 2016. Data from the observation period were derived from statistics published on the Statistics South Africa website and are available online [16]. Suicide was defined as a death resulting from intentional self-harm according to the World Health Organisation (WHO) International Statistical Classification of Diseases and Related Health Problems 10th revision (ICD-10), which uses codes X60 to X84 and Y87 to identify this outcome. Methods of suicide were classified into hanging (X70), drowning (X71), self-poisoning (X60-X69), firearm discharge and explosive material (X71-X75), blunt or sharp objects (X78-X79), fire, heat and hot substances (X76-X77), jumping from a high place or moving object (X80-X81), crashing of motor vehicle (X82) and unspecified means (X83-X84). Ill-defined or unknown causes of death (R99) was $11.6 \%$ in total and ranged from $3.1 \%$ to $6.5 \%$ annually, from 1997 to 2016.

Occupation groups were categorised according to the South African Standard Classification of Occupations (SASCO): managers, professionals, technicians, clerks, service workers and armed forces personnel, skilled agricultural workers, craft and related trade workers, plant and machine operators, elementary workers and unspecified occupations or persons not economically active [17]. Elementary workers included occupations such as cleaners, agricultural and forestry labourers or farm workers and refuse workers.

\subsection{Statistical Analysis}

We used mid-year population estimates to calculate age-standardised suicide mortality rates (ASMR) by sex for all years, except for 1997 to 2001, where mid-year population by age group was not available. We used the 1996 South African census data to calculate ASMRs for 1997 to 2000, and the 2001 census data was used for that year. The rates were standardised to the WHO standard population [18]. Individuals for whom sex or age was unspecified or unknown were not included in the analyses.

As ASMRs are influenced by deaths in older populations and the distribution of suicide mortality rates are high among younger adults as well as older populations [8], we calculated years of potential life lost (YPLL) as a measure of premature mortality that estimates the average time a person would have lived if death had not occurred prematurely [19]. The YPLL method assumes that if the person has not died from suicide, they would have lived until 65 years of age. To account for the changes in the population age-structure over time, YPLL was standardised to the WHO standard population. 
We used joinpoint regression analyses to identify changes in age-standardised suicide mortality trends in men and women. Joinpoint regression is a particular type of spline regression analysis [20] that explains the relationship between two variables, in which the spline segments are constraint to be linear. We analysed changes in trends in suicide mortality by sex, over 20 years, by fitting a regression line to the natural logarithm of the suicide rates, using the year of death as a regression variable. The changes in mortality rates were summarised as (increased, decreased or remained stable) annual percentage change (APC) and 95\% confidence intervals. We used the Surveillance Epidemiology and End Results statistical software (Joinpoint Regression Program, Version 4.5.0.1, National Cancer Institute, Bethesda, MD, USA) to determine the minimum number of change points, called joinpoints, by applying a permutation procedure described by Kim et al. [21,22]. The selection of change points or joinpoints was determined using the grid method described by Lerman et al. [23], and the number of significant points was determined using several permutation tests, and the overall $p$-value was tested using Bonferonni correction. A significance level of 0.05 was used for the permutation test with 4499 of randomly permuted datasets.

Multiple logistic regression analysis was performed to identify socio-demographic factors associated with suicide and method of suicide. Variables with $p$-values of $<0.10$ in the univariate analysis were included in the multivariate analysis. The final model is presented using mortality odds ratios (MORs) and 95\% confidence intervals (CI). Level of significance was set at 0.05 . Data were cleaned and analysed using Microsoft Excel 2013 and STATA version 15.

\section{Results}

\subsection{Description of the Study Population}

During the 20-year observation period (1997 to 2016), there were approximately 8.9 million recorded deaths in people 15 years and older in South Africa, of which $8573(0.1 \%)$ deaths were due to suicide. Men accounted for $78.1 \%$ (6699) of the total suicide deaths. The mean age of suicide deaths was similar among men ( $35 \pm 14.9$ years) and women $(35 \pm 18.2$ years, $p=0.535)$. Suicide deaths were more prevalent in December (11.7\%) and January (9.2\%) and lowest in winter (May to July, the average prevalence of $7.2 \%)$.

The socio-demographic characteristics of persons who died by suicide from 1997 to 2016 are summarised in Table 1. Deaths due to suicide significantly increased across five-year intervals from 1997 to 2016 (nptrend, $p<0.001$ ). Men were nearly three times more likely to die by suicide than women (adjMOR $=2.68,95 \%$ CI 2.49-2.89). Approximately 73\% (6237) of all suicides occurred in men and women aged 15 to 44 years. However, the odds of dying by suicide was highest among 15- to 29-year age group (adjMOR $=8.42,95 \%$ CI 7.31-9.70). Black African men accounted for $52 \%$ of all suicide deaths. Asian or Indian women had the lowest prevalence of suicide (0.48\%). Persons with any education (primary school and above) had increased odds of dying by suicide compared with persons who had no education or having attained grade $\mathrm{R}$ level education. The risk of dying by suicide increased as education level increased (nptrend, $p<0.001$ ). Persons who smoked five years before their death and for at least six months were more likely to die by suicide than those who did not smoke (adjMOR $=1.24,95 \%$ CI 1.15-1.32). Among those employed, elementary occupations had the highest prevalence of suicide (35.4\%), followed by service and armed forces (14.8\%). Compared to technicians, elementary occupations (adjMOR $=1.69,95 \%$ CI 1.06-2.71), skilled agricultural workers (adjMOR $=2.72,95 \%$ CI 1.64-4.51) and service workers and armed forces personnel (adjMOR = 1.88, $95 \%$ CI 1.16-3.06) were more likely to die by suicide. While $27 \%$ of suicide deaths occurred at home, and $20 \%$ died in a hospital or emergency room, for the largest proportion of suicides, the place of suicide deaths was unknown (44\%). 
Table 1. Crude and adjusted suicide mortality odds ratios (MOR) of socio-demographic factors associated with suicide mortality in adults, 15 years and older $(n=8573)$.

\begin{tabular}{|c|c|c|c|c|c|c|}
\hline Characteristic & n (\%) & Crude MOR $^{a}$ & $95 \%$ CI & Adjusted MOR ${ }^{a}$ & $95 \%$ CI & $p$-Value \\
\hline \multicolumn{7}{|l|}{ Years } \\
\hline 1997-2001 & 1405 (16.4) & Reference & & Reference & & \\
\hline 2002-2006 & $2318(27.1)$ & 1.12 & $1.05-1.20$ & 1.03 & $0.93-1.14$ & 0.571 \\
\hline 2007-2011 & $2142(24.9)$ & 1.03 & $0.96-1.10$ & 1.07 & $0.96-1.18$ & 0.215 \\
\hline $2012-2016$ & $2708(31.6)$ & 1.57 & $1.47-1.67$ & 1.67 & $1.15-1.85$ & $<0.001$ \\
\hline \multicolumn{7}{|l|}{ Sex } \\
\hline Female & 1855 (21.9) & Reference & & Reference & & \\
\hline Male & $6699(78.1)$ & 3.33 & $3.16-3.50$ & 2.68 & $2.49-2.89$ & $<0.001$ \\
\hline \multicolumn{7}{|l|}{ Broad age-group } \\
\hline $15-29$ & $3656(42.7)$ & 17.57 & $15.99-19.28$ & 8.42 & $7.31-9.70$ & $<0.001$ \\
\hline $30-44$ & $2581(30.1)$ & 6.50 & $5.90-7.16$ & 3.79 & $3.29-4.33$ & $<0.001$ \\
\hline $45-59$ & $1301(15.2)$ & 4.02 & $3.62-4.45$ & 2.19 & $1.91-2.53$ & $<0.001$ \\
\hline $60-74$ & $536(6.3)$ & 1.75 & $1.54-1.98$ & 0.84 & $0.69-1.01$ & 0.065 \\
\hline 75 and over & $499(5.82)$ & Reference & & & & \\
\hline \multicolumn{7}{|l|}{ Population group } \\
\hline Black African & $5594(65.3)$ & Reference & & Reference & & \\
\hline Indian or Asian & $156(1.8)$ & 1.24 & $1.15-1.35$ & 1.36 & $1.13-1.64$ & 0.001 \\
\hline White & $763(8.9)$ & 1.25 & $1.07-1.47$ & 2.52 & $1.13-1.64$ & $<0.001$ \\
\hline Coloured & $958(11.2)$ & 2.12 & $1.99-2.27$ & 1.64 & $1.45-1.84$ & $<0.001$ \\
\hline \multicolumn{7}{|l|}{ Marital status } \\
\hline Widowed/divorced & $531(6.2)$ & Reference & & Reference & & \\
\hline Never married & $5739(67.2)$ & 2.88 & $2.64-3.16$ & 1.02 & $0.90-1.17$ & 0.670 \\
\hline Married & $1610(18.8)$ & 1.77 & $1.60-1.96$ & 1.13 & $0.99-1.29$ & 0.065 \\
\hline \multicolumn{7}{|l|}{ Educational attainment } \\
\hline None/Grade R & $420(8.7)$ & Reference & & Reference & & \\
\hline Primary education & $1221(25.1)$ & 1.83 & $1.63-2.04$ & 1.13 & $1.02-1.28$ & 0.024 \\
\hline Secondary & $2897(59.7)$ & 3.23 & $2.91-3.58$ & 1.49 & $1.34-1.67$ & $<0.001$ \\
\hline Tertiary & $313(6.5)$ & 3.46 & $2.99-4.00$ & 1.63 & $1.39-1.91$ & $<0.001$ \\
\hline \multicolumn{7}{|l|}{ Smoking status of deceased } \\
\hline No & $2150(25.1)$ & Reference & & Reference & & \\
\hline Yes & $1966(22.9)$ & 2.05 & $1.93-2.19$ & 1.24 & $1.15-1.32$ & $<0.001$ \\
\hline Unknown/unspecified & $4457(51.9)$ & 1.02 & $0.97-1.07$ & 1.37 & $0.73-2.55$ & 0.321 \\
\hline \multicolumn{7}{|l|}{ Province of death } \\
\hline Free State & $489(5.7)$ & Reference & & Reference & & \\
\hline Kwa-Zulu Natal & $2690(31.5)$ & 1.99 & $1.81-2.19$ & 1.98 & $1.77-2.21$ & $<0.001$ \\
\hline Western Cape & $1094(12.8)$ & 2.02 & $1.82-2.25$ & 1.10 & $0.93-1.31$ & 0.252 \\
\hline Eastern Cape & $972(11.4)$ & 1.09 & $0.98-1.22$ & 1.00 & $0.88-1.16$ & 0.899 \\
\hline Northern Cape & $932(10.9)$ & 5.70 & $5.11-6.36$ & 5.15 & $4.48-5.91$ & $<0.001$ \\
\hline Mpumalanga & $683(8.0)$ & 1.51 & $1.34-1.69$ & 1.00 & $0.86-1.16$ & 0.987 \\
\hline North West & $612(7.2)$ & 1.07 & $1.21-1.53$ & 1.37 & $1.18-1.61$ & $<0.001$ \\
\hline Limpopo & $571(6.7)$ & 1.31 & $0.95-1.21$ & 1.00 & $0.87-1.17$ & 0.939 \\
\hline Gauteng & $482(5.7)$ & 0.39 & $0.34-0.44$ & 0.34 & $0.28-0.39$ & $<0.001$ \\
\hline \multicolumn{7}{|l|}{ Occupation groups } \\
\hline Technicians & $25(0.3)$ & Reference & & Reference & & \\
\hline Managers & $36(0.4)$ & 1.37 & $0.82-2.82$ & 1.54 & $0.86-3.06$ & 0.138 \\
\hline Professionals & $70(0.8)$ & 1.03 & $0.65-1.63$ & 1.63 & $0.97-2.73$ & 0.064 \\
\hline Clerks & $36(0.4)$ & 1.09 & $0.65-1.81$ & 1.69 & $0.57-1.81$ & 0.338 \\
\hline $\begin{array}{l}\text { Service workers and armed } \\
\text { forces }\end{array}$ & 139 (1.6) & 1.85 & $1.21-2.84$ & 1.88 & $1.16-3.06$ & 0.011 \\
\hline Skilled agricultural workers & $92(1.1)$ & 2.62 & $1.68-4.09$ & 2.72 & $1.64-4.51$ & $<0.001$ \\
\hline Craft \& related trade workers & $101(1.2)$ & 1.24 & $0.80-1.92$ & 1.26 & $0.76-2.08$ & 0.361 \\
\hline Plant \& machine operators & $107(1.3)$ & 1.40 & $0.91-2.18$ & 1.52 & $0.61-1.91$ & 0.096 \\
\hline Elementary occupations & $332(3.9)$ & 1.25 & $0.83-1.88$ & 1.69 & $1.06-2.71$ & 0.027 \\
\hline $\begin{array}{l}\text { Unspecified occupations or not } \\
\text { economically active }\end{array}$ & $7635(89.1)$ & 0.90 & $0.61-1.33$ & 1.94 & $1.23-3.06$ & 0.004 \\
\hline \multicolumn{7}{|l|}{ Place of death } \\
\hline Hospital & $1628(19.0)$ & Reference & & Reference & & \\
\hline Home & $2301(26.8)$ & 2.21 & $2.08-2.36$ & 2.26 & $2.08-2.46$ & $<0.001$ \\
\hline Dead on arrival & $597(7.0)$ & 6.94 & $6.31-7.62$ & 3.84 & $3.40-4.31$ & $<0.001$ \\
\hline Emergency room & $165(1.9)$ & 2.62 & $2.23-3.08$ & 1.84 & $1.48-2.27$ & $<0.001$ \\
\hline Nursing home & $77(0.9)$ & 0.96 & $0.76-1.21$ & 1.21 & $0.87-1.67$ & 0.256 \\
\hline Unspecified & $3805(44.4)$ & 4.34 & $4.09-4.60$ & 3.37 & $3.11-3.66$ & $<0.001$ \\
\hline
\end{tabular}

${ }^{\text {a }}$ MOR-mortality odds ratio. 


\subsection{Trends in Suicide Mortality}

From 1997 to 2016, suicide rates per 100,000 population were 2.07 in men and 0.49 in women. Men had consistently higher suicide mortality rates than women from 1997 to 2016 (Figure 1). The highest observed mortality rate for men in the time series was 3.16 deaths per 100000 population in 2005.

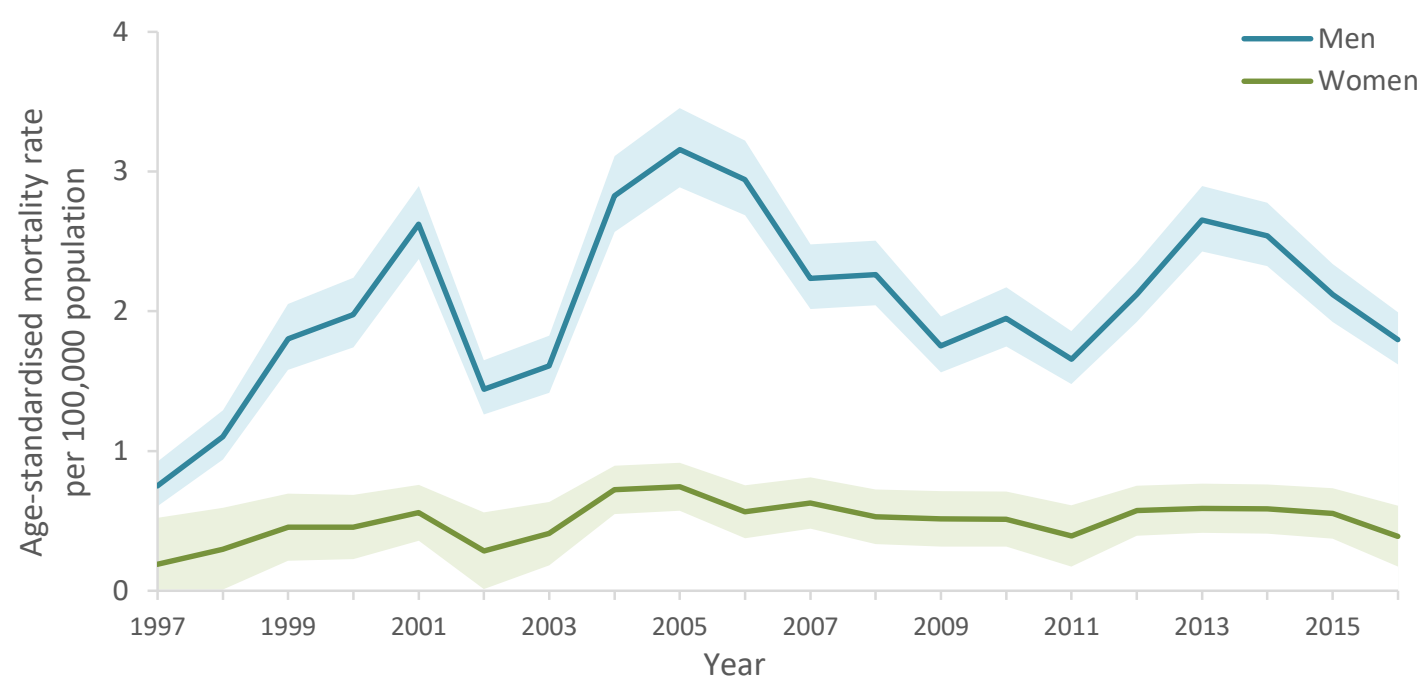

Figure 1. Age-standardised suicide mortality rate (95\% CI bands) by sex in South Africa, 1997-2016.

The joinpoint regression analyses identified one change point or joinpoint for men (2001) and women (2004), resulting in two linear segments or changes in the mortality rate (Figure 2). The mortality rate remained stable for men within each period identified by the model, as the increase in mortality rates from 1997 to 2001 ( APC $=29.5 \%, 95 \%$ CI 0-67.8) and decrease in mortality rates from 2001 to 2016 (APC $=-1.2 \%, 95 \%$ CI 4.2-2.0) were not significant. The mortality rate for women increased significantly by $12.6 \%$ (95\% CI 1.5-25.0) from 1997 to 2004 and then stabilised.

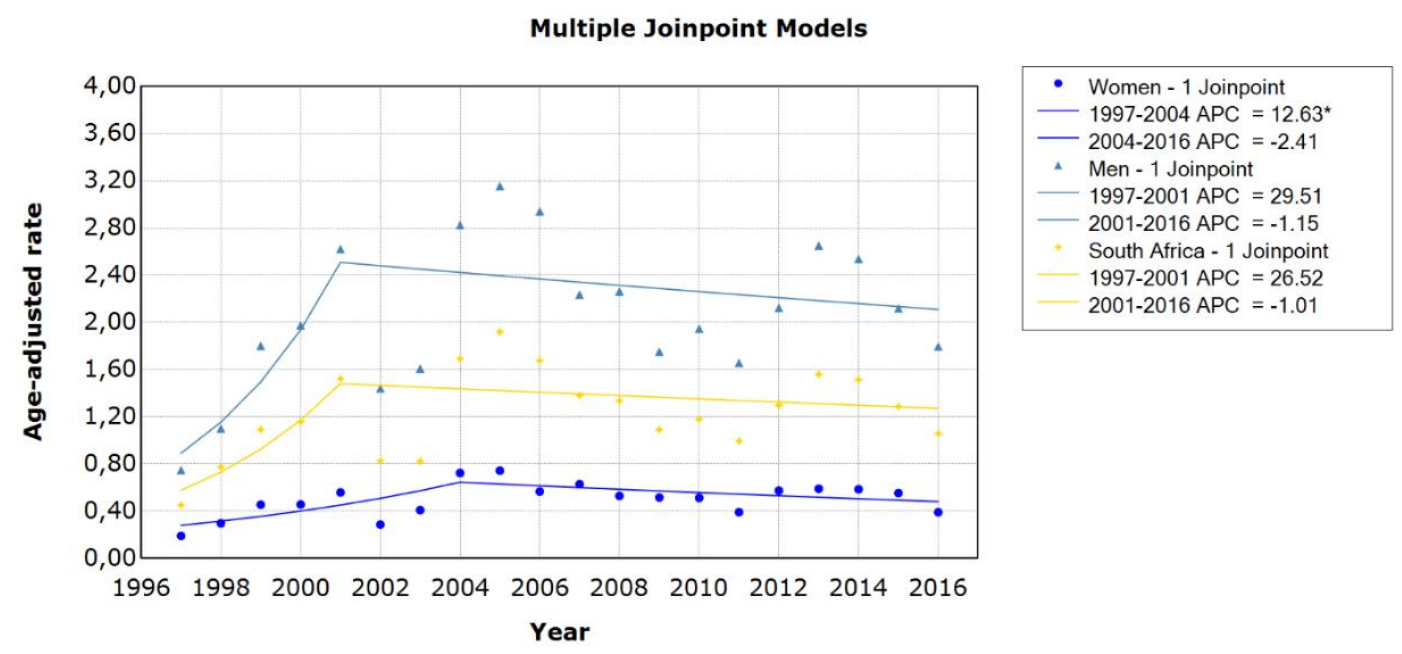

Figure 2. Trends in age-standardised suicide mortality rates in men and women in South Africa using joinpoint regression analysis. Data markers represent observed rates; lines represent joinpoint regression using one joinpoint; $\mathrm{APC}=$ annual percentage change; ${ }^{*}$ indicates that the APC is significantly different from zero at the alpha $=0.05$ level. 


\subsection{Suicide Patterns by Age}

Age-specific suicide rates varied substantially in men compared to women (Figure 3). In the late 1990s, suicide rates increased with age, and men 75 years and older had the highest suicide rate $(1.61$ deaths per 100,000). In 2006, mortality rates were high in men across all age groups. However, in 2016, men aged 15 to 29 years had the highest suicide rate (2.1 deaths per 100,000 population), followed by 30 - to 44-year age group (1.8 deaths per 100,000) and gradually declined with age. In contrast, suicide mortality in women was consistently higher among those older than 75 years from 2006 onwards.

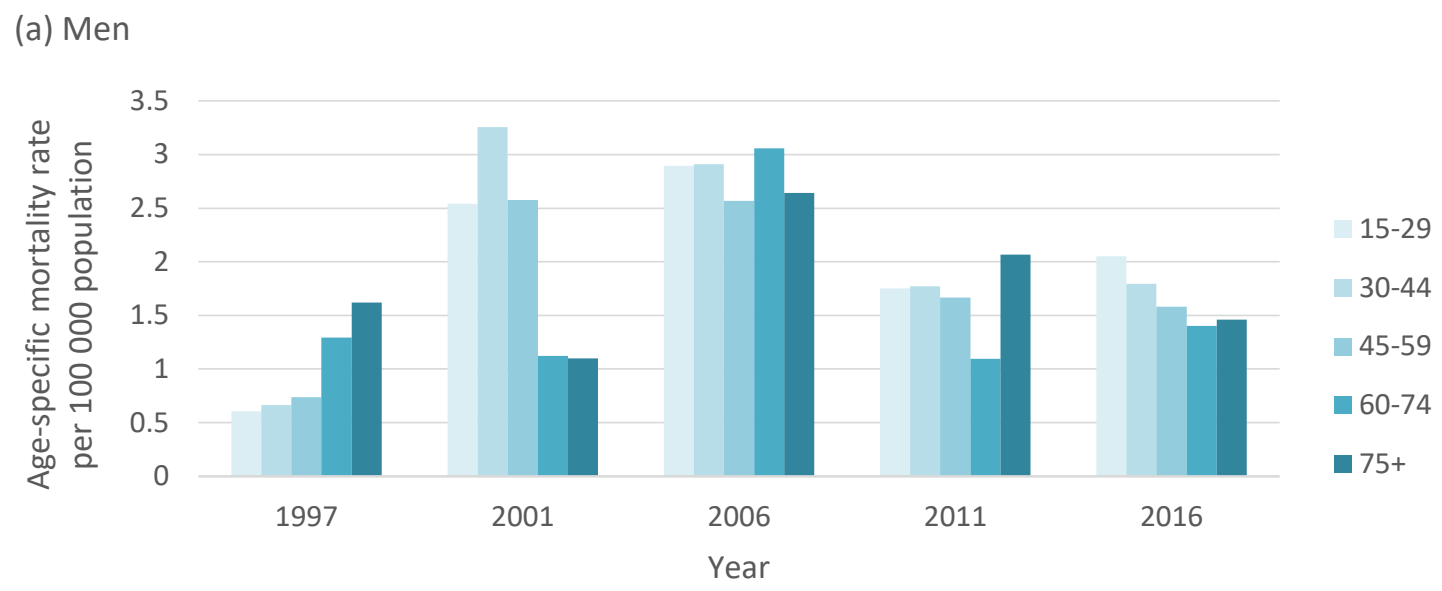

(b) Women

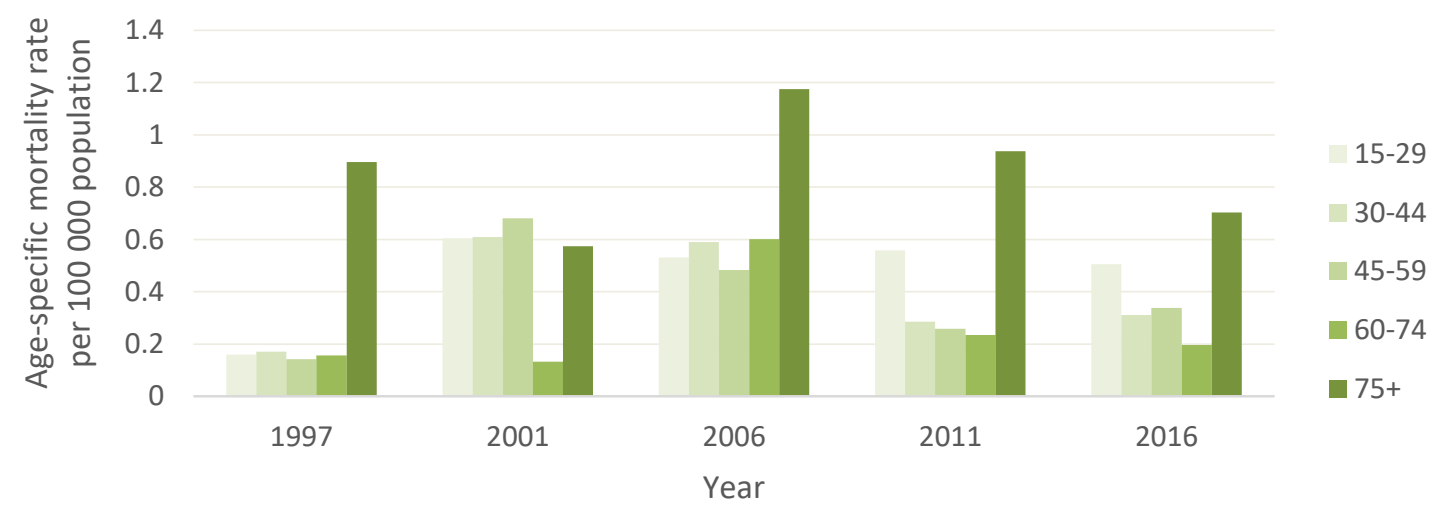

Figure 3. Age-specific suicide rates in men and women by broad age groups in South Africa across 5-year intervals. (a) Men; (b) Women.

\subsection{Trends in Suicide Methods}

In Figure 4, from 1997 to 2016, hanging was the leading method of suicide in men, accounting for $4057(60.6 \%)$ deaths, followed by poisoning (drug poisoning, 5.3\%; pesticide poisoning, $1.7 \%$, poisoning by other means, $7.4 \%$ ) and firearm use $(578,8.6 \%)$. Poisoning was the leading method of suicide in women (drug poisoning, $21.9 \%$; pesticide poisoning, $5.0 \%$ and poisoning by other means, $12.9 \%)$, followed closely by hanging $(36.1 \%)$. Deaths due to pesticide poisoning and drugs in the total population were $2.4 \%$ (208) and $8.7 \%$ (766), respectively. Approximately $6 \%$ of all suicides were not classified (X83-X84). 


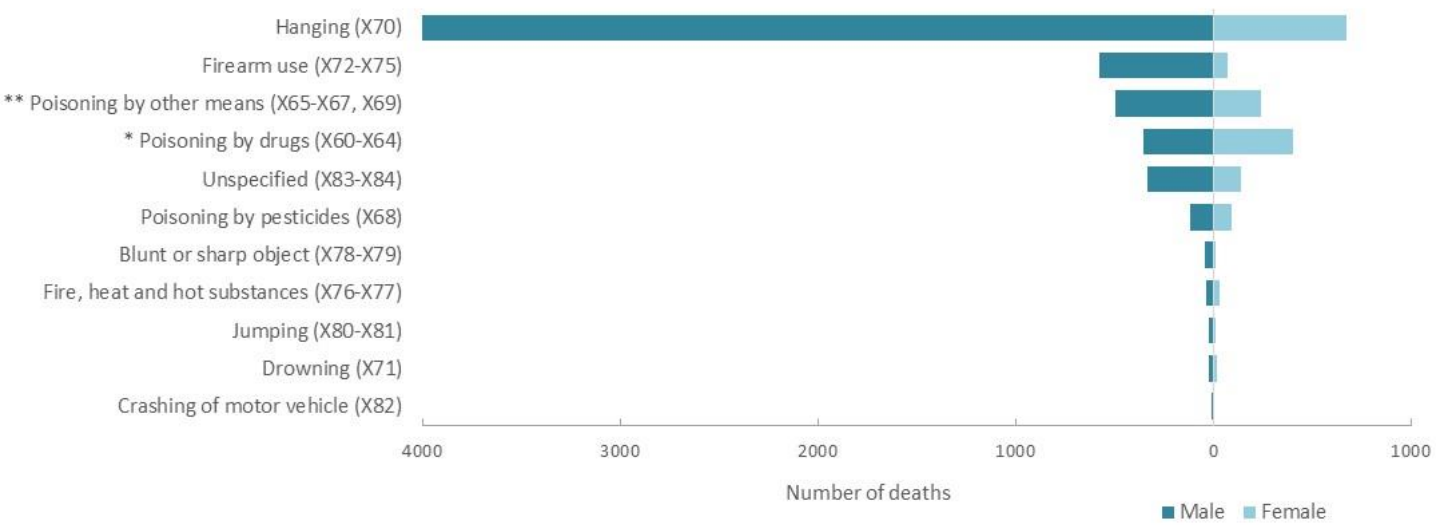

Figure 4. Number of deaths by method of suicide, 1997 to $2016 .{ }^{*}$ Drug poisoning include medication such as analgesics, ingestion of analgesics, antiepileptic medication; narcotics and other drugs acting on the autonomic nervous system; ${ }^{* *}$ poisoning by other means includes unspecified drugs, organic solvents, gases and vapours and unspecified chemicals.

Trends in the method of suicide varied substantially by sex (Figure 5). Hanging was the leading method of suicide in men for the study period, followed by poisoning and the use of firearms. In women, both hanging and poisoning were common methods of suicide.

(a) Men
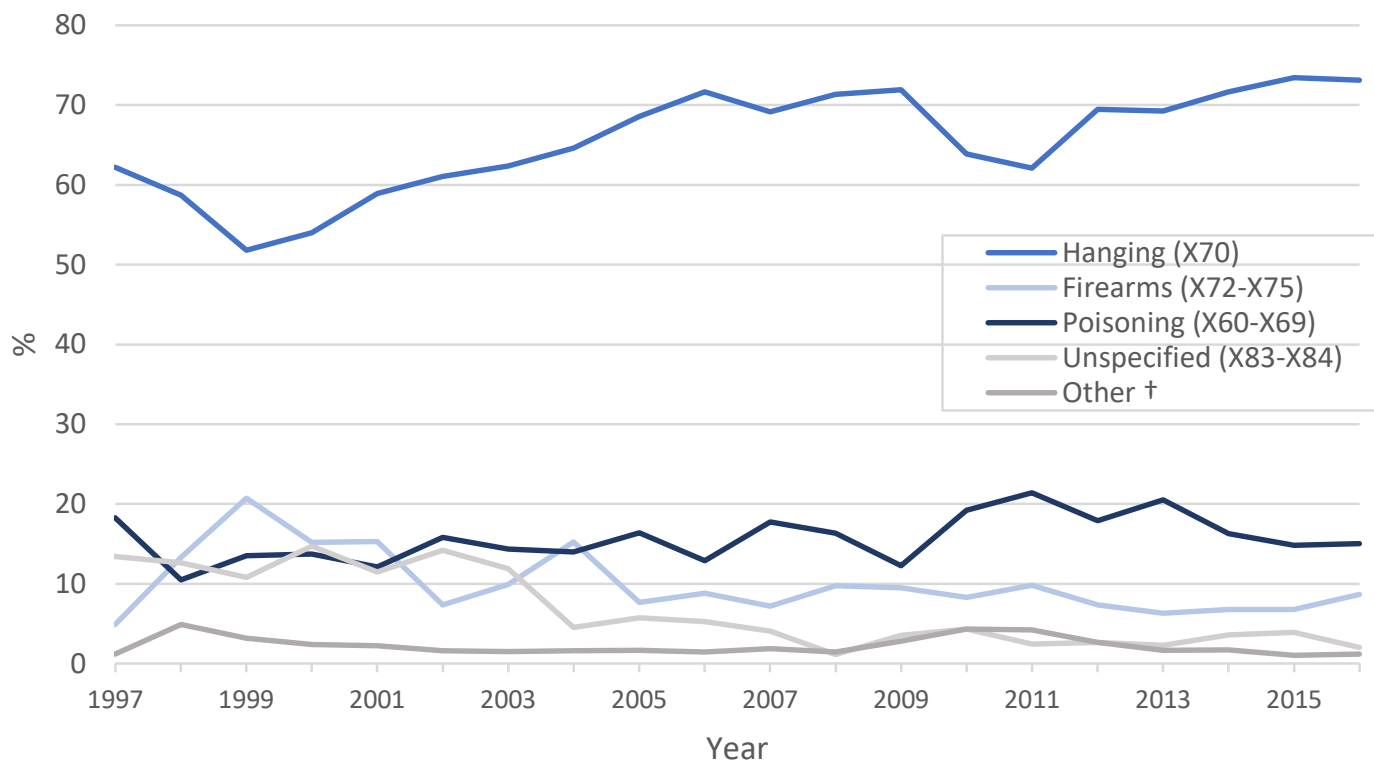

Figure 5. Cont. 
(b) Women

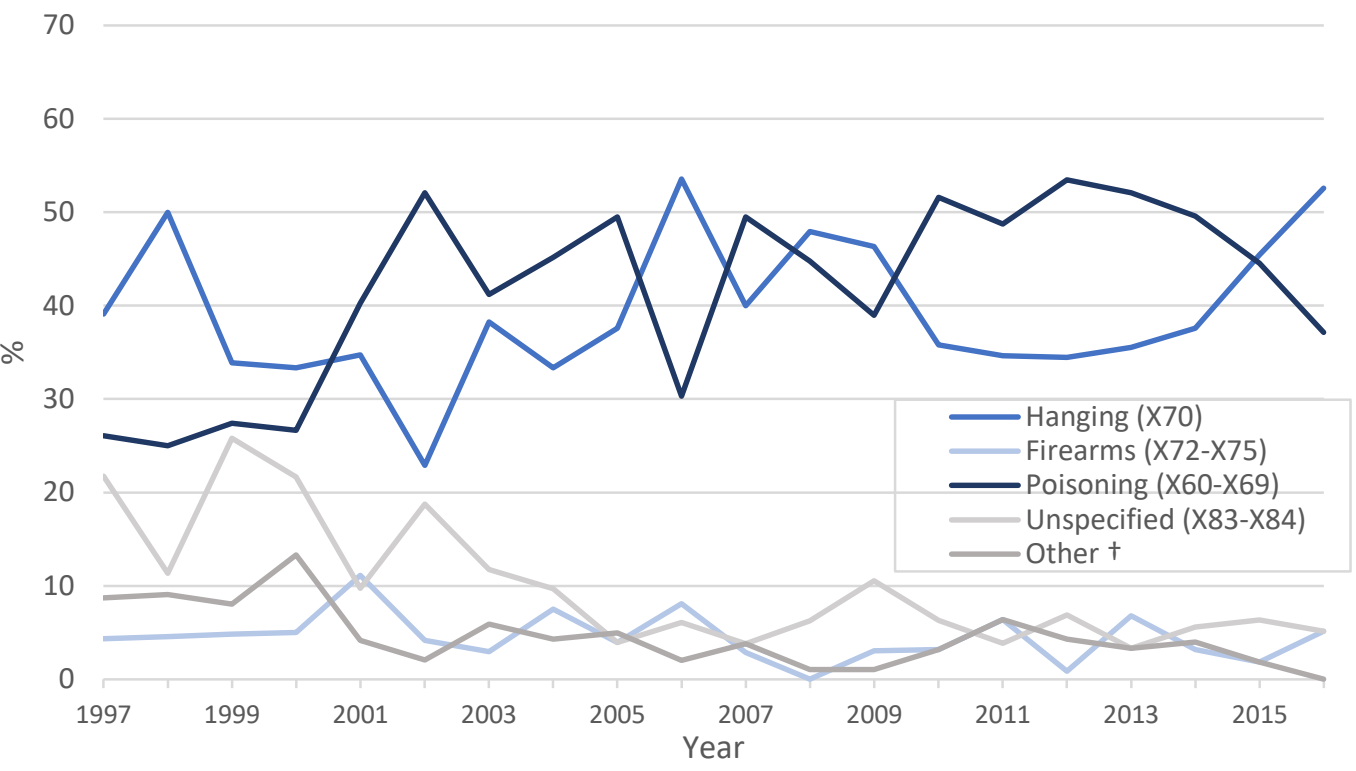

Figure 5. Proportion of suicide by method in (a) men and (b) women in South Africa, 1997 to 2016; + other includes intentional self-harm by drowning (X71), fire, heat and hot substances (X76-X77), blunt or sharp object (X78-X79), jumping from a high place or moving object (X81) and crashing of motor vehicle (X82). (a) Men; (b) Women.

Joinpoint regression analysis (Figure 6) shows that deaths due hangings in men and women increased significantly by $3.5 \%$ (95\% CI $1.1 \%$ to $6.0 \%$ ) and 3.0\% (95\% CI $0.6 \%$ to $5.4 \%)$, respectively, from 1997 to 2016 . Suicide by poisoning increased significantly by $3.9 \%$ (95\% CI $1.8 \%$ to $6.0 \%$ ) in men from 1997 to 2016. In female suicides, poisoning increased by an average annual percentage change of $6.7 \%$ (95\% CI $2.3 \%$ to $11.3 \%$ ) over the 20 -year period, showing a particularly sharp increase of $17 \%$ (95\% CI 7.1\% to 28.0\%) per year from 1997 to 2005, before stabilising. Firearm use in men showed an annual decrease by $1.2 \%$ from 1997 to 2016, but it was not significant (95\% CI $4.0 \%$ to $1.6 \%$ ). Trends for firearm use in women could not be assessed as there were no reported deaths by firearm use in 2008 .

(a) Men

Multiple Joinpoint Models
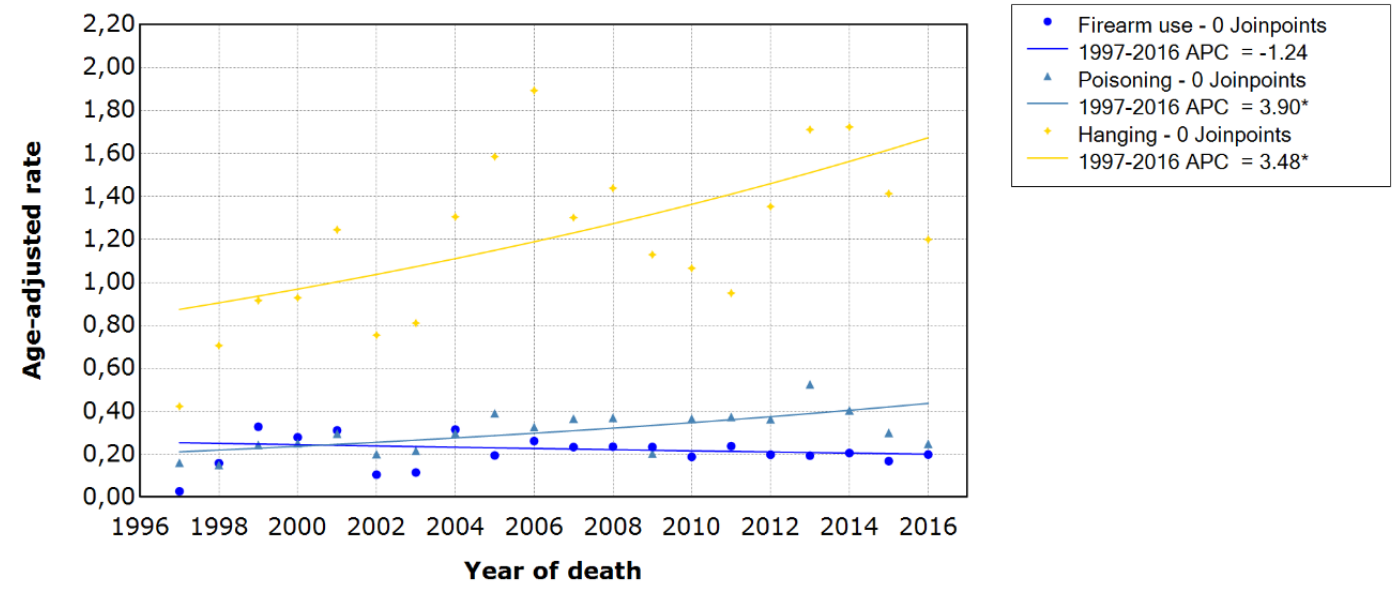

Figure 6. Cont. 
(b) Women

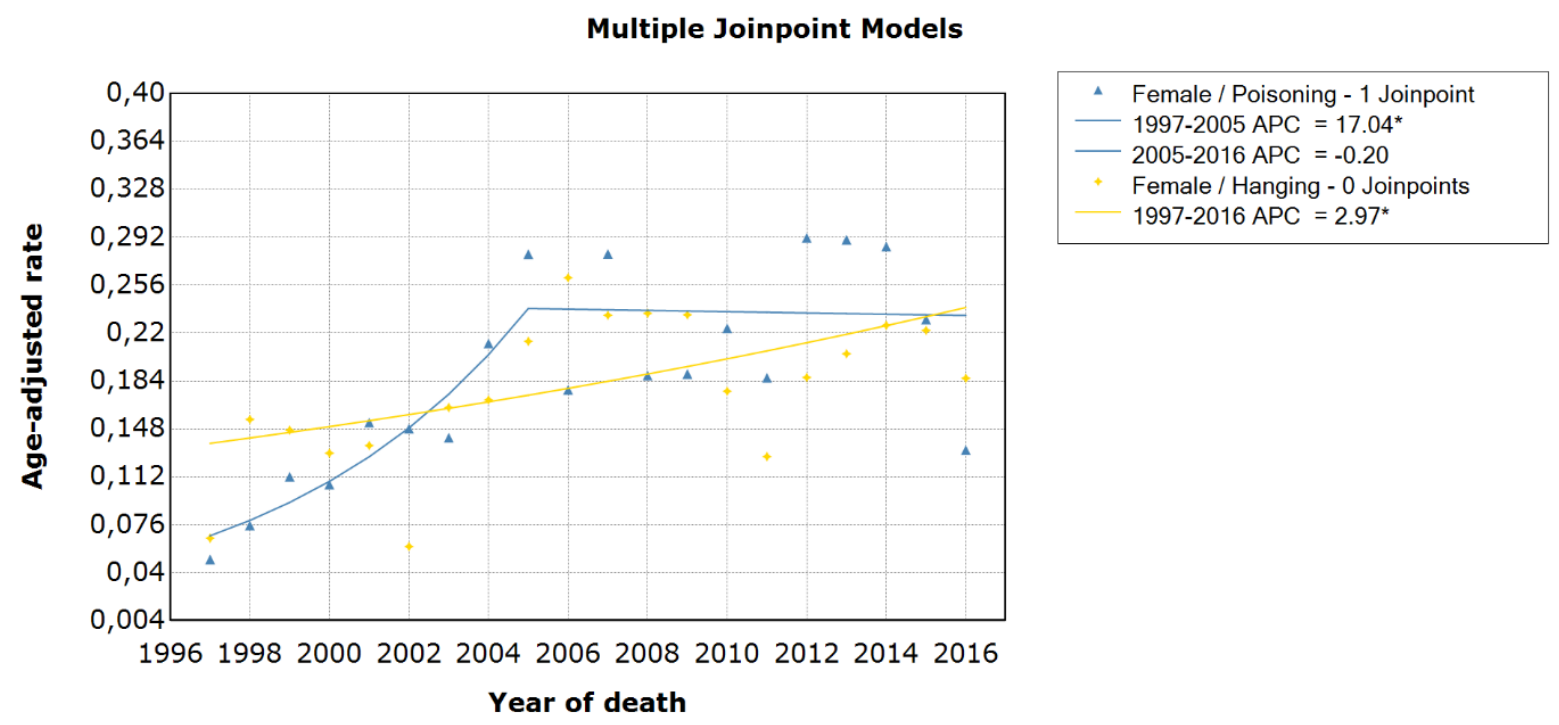

Figure 6. Trends in age-standardised mortality rates by the method of suicide in (a) men and (b) women in South Africa using joinpoint regression analysis. Data markers represent observed rates; lines represent joinpoint regression using no join points or one join point for poisoning in women. Joinpoint regression analysis for firearm use in women could not process records with dependent variable $=0 ; \mathrm{APC}=$ annual percentage change; ${ }^{*}$ indicates that the APC is significantly different from zero at the alpha $=0.05$ level. (a) Men; (b) Women.

The distribution of the methods of suicide by broad age groups is shown in Figure 7. Hanging was the most common method of suicide in men across all age groups over the entire observation period and was more evident in young men aged 15 to 29 years and older men, 75 years and older. The use of firearms was most prevalent among men aged 60 to 74 years and in women aged 45 to 49 years. Poisoning was the most common method of suicide among younger women of 15 to 59 years, whereas older women of 60 years and older died by hanging.

(a) Men

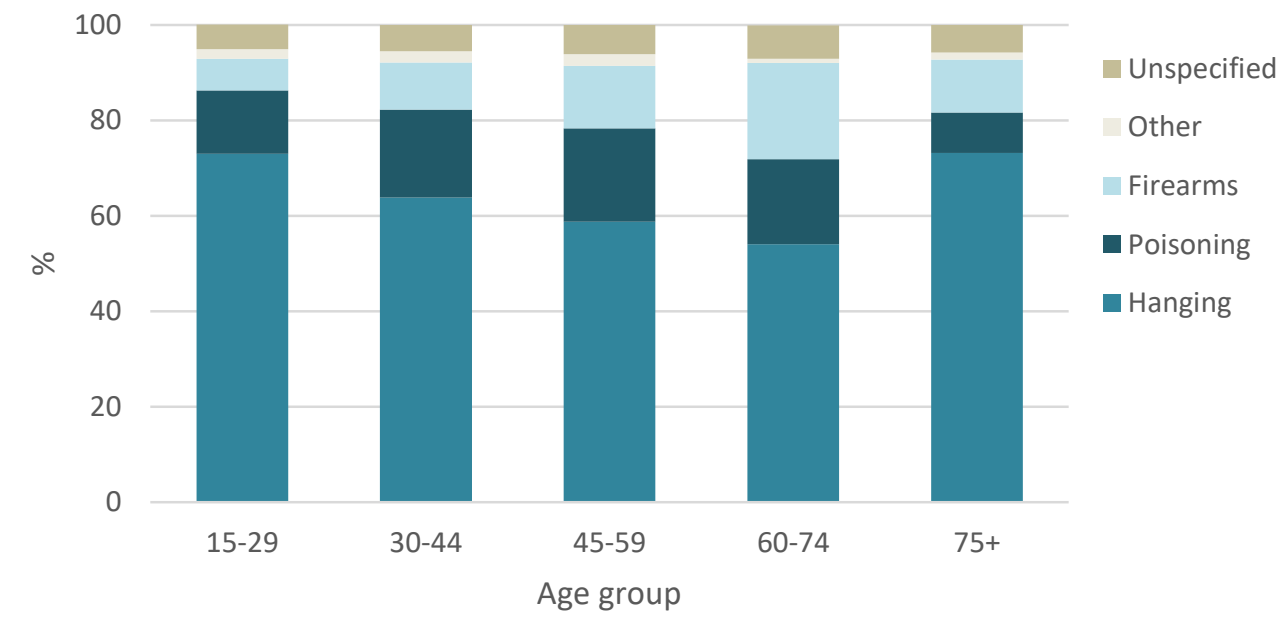

Figure 7. Cont. 
(b) Women

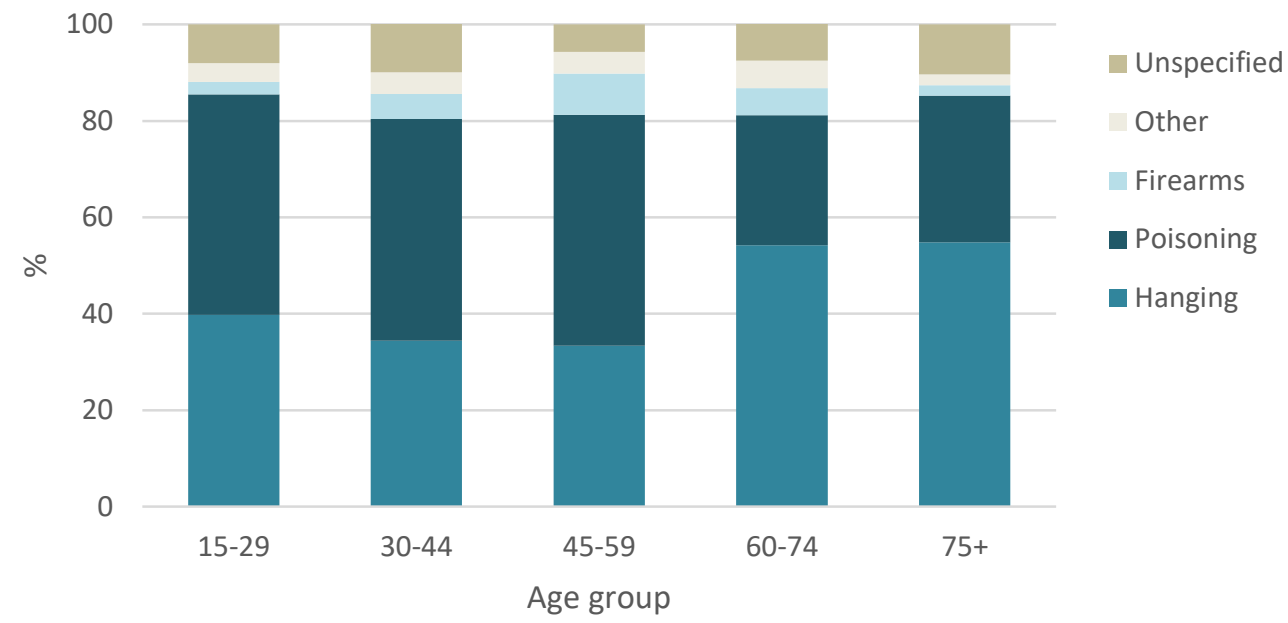

Figure 7. Distribution of suicides by method for broad age groups for men and women, South Africa, 1997-2016. (a) Men; (b) Women.

Table 2 describes the method of suicide by occupation group. Of the 877 (10.2\%) suicides who had specified an occupation, hanging was a common method used by elementary workers (41.3\%), service workers and armed forces (12.7\%) and plant and machine operators (12.5\%). Firearm use was prevalent among service workers and armed forces (34.8\%), skilled agricultural workers $(13.9 \%)$ and managers $(10.4 \%)$. Suicide by pesticide poisoning was a method most used by elementary workers, a large group that includes farm labourers (38.5\%), and skilled agricultural workers (26.9\%).

Table 2. Methods of suicide by occupation group $(n=877)$.

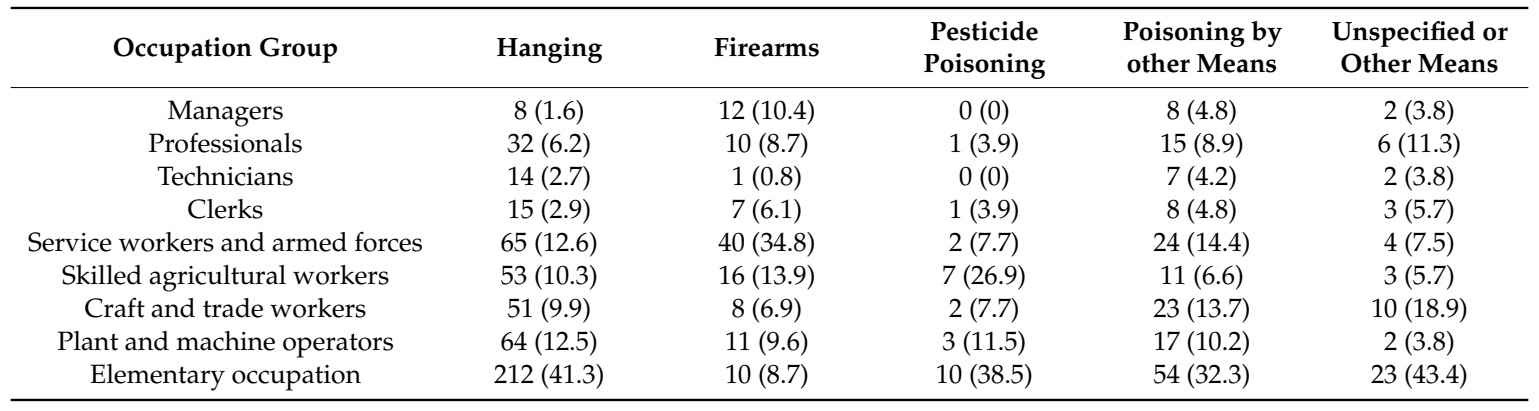

\subsection{Years of Potential Life Lost}

In South Africa, the burden of premature mortality was estimated as a total of 37,310,985 YPLL for all causes of death from 1997 to 2016, and less than 1\% (0.65\%, 243,429 YPLL) were due to suicide (Table 3). The average annual loss due to suicide was 9559 YPLL (rate, 5.73 per 10,000 population) among men and 2612 YPLL (rate, 1.49 per 10,000 population) among women. YPLL rates were highest in 2004 and 2005 for men, and in 2004 and 2014 for women. 
Table 3. Years of potential life lost (YPLL) estimates by all causes of death and suicide-specific cause of death by year and sex.

\begin{tabular}{|c|c|c|c|c|c|c|c|c|}
\hline \multirow{3}{*}{ Year } & \multicolumn{4}{|c|}{ Male } & \multicolumn{4}{|c|}{ Female } \\
\hline & \multicolumn{2}{|c|}{ All Causes (YPLL) } & \multicolumn{2}{|c|}{$\begin{array}{c}\text { Suicide-Specific } \\
\text { (YPLL) }\end{array}$} & \multicolumn{2}{|c|}{ All Causes (YPLL) } & \multicolumn{2}{|c|}{$\begin{array}{l}\text { Suicide-Specific } \\
\text { (YPLL) }\end{array}$} \\
\hline & $\begin{array}{l}\text { Total } \\
\text { YPLL }\end{array}$ & $\begin{array}{c}\text { Rate Per } \\
1000\end{array}$ & $\begin{array}{l}\text { Total } \\
\text { PYLL }\end{array}$ & $\begin{array}{c}\text { Rate Per } \\
1000^{a}\end{array}$ & $\begin{array}{l}\text { Total } \\
\text { PYLL }\end{array}$ & $\begin{array}{c}\text { Rate Per } \\
1000^{a}\end{array}$ & $\begin{array}{l}\text { Total } \\
\text { PYLL }\end{array}$ & $\begin{array}{c}\text { Rate Per } \\
1000^{a}\end{array}$ \\
\hline 1997 & $2,398,233$ & 209,88 & 2325 & 0.20 & $1,471,662$ & 116.12 & 595 & 0.04 \\
\hline 1998 & $2,792,467$ & 244,48 & 3912 & 0.29 & $1,862,922$ & 145.78 & 1237 & 0.09 \\
\hline 1999 & $2,997,012$ & 262,39 & 6595 & 0.51 & $2,223,997$ & 172.00 & 1805 & 0.13 \\
\hline 2000 & $3,263,040$ & 286,10 & 6625 & 0.52 & $2,694,757$ & 207.61 & 2035 & 0.14 \\
\hline 2001 & $3,598,960$ & 274,09 & 11,635 & 0.78 & $3,135,470$ & 207.78 & 2712 & 0.17 \\
\hline 2002 & $3,988,685$ & 296,95 & 6297 & 0.42 & $3,737,317$ & 248.45 & 1667 & 0.09 \\
\hline 2003 & $4,421,255$ & 323,76 & 6967 & 0.45 & $4,295,517$ & 281.71 & 2007 & 0.12 \\
\hline 2004 & $4,555,435$ & 328,59 & 11,152 & 0.72 & $4,638,935$ & 300.71 & 3330 & 0.20 \\
\hline 2005 & $4,653,162$ & 330,58 & 13,457 & 0.85 & $4,725,847$ & 302.97 & 3322 & 0.19 \\
\hline 2006 & $4,717,585$ & 328,82 & 13,370 & 0.81 & $4,707,187$ & 297.83 & 2712 & 0.16 \\
\hline 2007 & $4,671,250$ & 319,02 & 10,507 & 0.62 & $4,483,875$ & 279.87 & 3237 & 0.18 \\
\hline 2008 & $4,580,495$ & 306,39 & 10,565 & 0.62 & $4,307,242$ & 264.37 & 2920 & 0.16 \\
\hline 2009 & $4,386,215$ & 276,70 & 8305 & 0.47 & $4,725,847$ & 282.27 & 2885 & 0.16 \\
\hline 2010 & $4,058,652$ & 260,99 & 8822 & 0.50 & $3,661,447$ & 216.78 & 2852 & 0.15 \\
\hline 2011 & $3,705,815$ & 233,27 & 8767 & 0.48 & $3,164,912$ & 184.45 & 2422 & 0.13 \\
\hline 2012 & $3,505,240$ & 214,99 & 11,500 & 0.60 & $2,860,962$ & 163.65 & 3532 & 0.18 \\
\hline 2013 & $3,356,222$ & 201,23 & 14,272 & 0.75 & $2,605,087$ & 146.71 & 3265 & 0.17 \\
\hline 2014 & $3,284,210$ & 192,78 & 14,370 & 0.75 & $2,457,035$ & 136.29 & 4065 & 0.21 \\
\hline 2015 & $3,249,292$ & 186,68 & 11,252 & 0.58 & $2,331,967$ & 127.35 & 3227 & 0.17 \\
\hline 2016 & $3,133,707$ & 175,98 & 10,485 & 0.53 & $2,187,140$ & 117.53 & 2422 & 0.13 \\
\hline Total & $28,015,087$ & 262,68 & 191,180 & $0.57^{b}$ & $9,295,898$ & $210.01^{b}$ & 52,249 & $0.15^{b}$ \\
\hline
\end{tabular}

\section{Discussion}

This study provides a profile of suicide mortality in South Africa over a 20-year period from 1997 to 2016. We report a male predominance in suicide rates that is consistent with previous findings in South Africa [7,11,24] and international trends, with a few exceptions such as India [25] and China [26]. Joinpoint regression analyses indicate that the overall trend in suicide mortality changed twice for men and women in the observation period. Suicide mortality rates in women significantly increased by $12.6 \%$ from 1997 to 2004 and then stabilised; mortality rates in men remained stable over the observation period, despite the fluctuations across the years.

We did not observe an overall decline in suicide mortality as reported by 2016 the Global Burden of Disease Study, where the largest significant decreases in mortality were observed in China, Denmark, the Philippines, Singapore and Switzerland [1]. Naghavi and colleagues reported increases in suicide mortality rates for LMICs such as Zimbabwe, and Zambia [1]. We observed wide year-on-year fluctuations in overall YPLL due to suicide but significant increases in the mortality rate of suicide by hanging for both sexes, while suicide by poisoning increased in men across the 20 years. Our results are consistent with findings from South Korea [27] and Norway [28], where increases in suicide rates by hanging for men and women have also been reported. Hanging was the most frequently used suicide method in South Africa, accounting for $47 \%$ of all suicide deaths, in keeping with previous South African studies $[7,11]$. A possible explanation for the increase in suicide by hanging may have been due to a substitution of other means [29], possibly due to the decrease in suicide by firearm use. During the study period, stricter gun control was applied in South Africa through the Firearms Control Act (FCA) of 2000; thus, stringent licencing conditions may have reduced access to firearms. Traditionally, women have chosen less lethal suicide methods such as poisoning while men chose 
highly lethal methods with such as hanging and firearm use [30]. In our study, men clearly chose hanging over other methods and women were as likely to die by hanging before 2000 and after 2015 . This is of particular concern, as hanging has a high fatality rate of more than $70 \%$ [31]. Furthermore, it presents a challenge with respect to prevention efforts, as hanging is often chosen for its easy access to everyday household items such as ropes and belts that can be used as ligatures [32].

Notable changes in suicide by poisoning were shown in men and women. We report an increase of nearly $4 \%$ in suicide poisonings in men annually, while poisoning in women had stabilised after 2004. The dominant method of poisoning was with drugs and was more prevalent among women than men. This finding is similar to an earlier study by Eddleston (2000) who reported that medicines constituted more than $70 \%$ of all suicide by poisoning in sub-Saharan Africa [33] and was more recently confirmed by a poison centre in Cape Town, South Africa [34]. Further research is therefore needed to establish whether the restriction of over the counter medication may assist in reducing access to lethal means. Pesticide poisoning accounts for $30 \%$ of all suicides in the world [35] and remains an important method of suicide in sub-Saharan Africa [5]. However, the prevalence of pesticide poisoning in our study was considerably lower than reported in Ethiopia [36] and Uganda [37] but was in keeping with findings from South African mortuary studies in Bloemfontein [12] and Cape Town [38].

Suicide mortality is often linked to easy occupational access to a specific method of suicide [10]. Our study reports increased odds of dying by suicide among elementary workers, service workers and armed forces and agricultural workers compared to technicians. Similar to our findings, occupations associated with the use of or access to firearms such as armed forces and policemen have reported higher levels of firearm suicides [39]. Higher socioeconomic occupations, such as managers, may also suggest easier access to firearms. The association between suicide by pesticide poisoning and agricultural occupations have been clearly described [40], and farmers, farmworkers and agricultural populations with access to pesticides are at increased risk of suicide [41]. Studies have shown that reducing the accessibility of suicide means have been associated with a reduction in suicide rates [29]. Thus, there is a need for future studies to investigate explanations for the observed differences across occupations in South Africa. In addition, we also reported an increased odds of suicide among unemployed individuals. Unemployment is an independent risk factor of suicide as it is associated with an increased risk of mental illness [42], vulnerability to stressful life conditions and often, can contribute towards a lack of social cohesion [43]. The highest suicide rates were observed among men in 2005. Among the multitude of social and economic determinants of suicide, the rising levels of unemployment in South Africa could partly explain why men, especially of working age, were particularly affected [44].

When analysing mortality rates by sex and age, the suicide rates were highest in men, aged 15 to 44 years, and women older than 75 years. These results have been confirmed by a forensic investigation by Matzopoulus et al. [6] and were similar to international studies [45]. Southern sub-Saharan Africa's age-standardised rate of years of life lost from suicide was estimated at 664.1 per 100000 in 2016 (men, 1056.6 YLL per 100,000 and women, 296.1 YLL per 100,000) [1]. We report a lower average annual loss due to suicide for men (9559 YPLL, rate, 57.3 per 100,000 population) and women (2612 YPLL, rate, 14.9 per 100,000 population) in South Africa, suggesting a relatively lower suicide rate adjusted for age and sex compared to southern sub-Saharan Africa. Nevertheless, the risk of suicide in young South African men of working age has economic implications and should be investigated further, especially in occupations, where the prevalence of suicide is high. Consequently, as suicide is more common among the young and the elderly in South Africa, both YPLL and suicide rates should be used for monitoring mental health programs in order to reduce premature mortality due to suicide.

Several reviews have linked suicide with social inequalities $[42,46]$. In low- and middle-income countries, completed suicide has been associated with poverty [47], unemployment [48] and debt [49] and low education levels [50]. We found that the risk of suicide increased with educational levels. This was comparable to an Italian study where individuals with higher educational attainment were at greater risk of suicide [51]. Being married was associated with an increased risk of suicide compared to 
widows or divorced. Interpersonal difficulties such as marriage problems, family conflict and domestic violence may play an important role [52]. We report seasonal variation of suicide among adults, with a higher prevalence of suicide reported in summer and lowest in winter. This finding is corroborated with an earlier study by Flischer et al. who suggested that changes in social activities and the possible influence of Christmas may increase the risk of suicide, especially among those living in less urban areas and with lower socioeconomic status [53].

\section{Strengths and Limitations}

This study has a few strengths. Firstly, this study consists of the analysis of a large national dataset and assessed changes in suicide mortality rates using joinpoint regression analyses. Joinpoint regression analysis calculates the annual percentage change in the mortality rates and can be used to study trends in suicide mortality over time. Secondly, this study provides estimates of years of potential life lost, which weighs death more heavily at a younger age than older individuals. Therefore, it provides additional information about the burden of premature death due to suicide.

Our findings are derived from data in the Statistics South Africa database, which are obtained from death certificates. The quality of the death certificates is the main limiting factor, and underreporting of suicide have been previously described in the vital registration data, which can result in an underestimation of the true mortality burden attributable to suicide in South Africa [6,54]. Ajdacic-Gross et al. also observed that less violent methods such as suicide by poisoning and drowning are more likely to be underreported compared to highly lethal methods such as hanging and firearm suicides $[5,9]$. Thus, caution is needed when interpreting trends, especially suicide, by poisoning. It was difficult to accurately assess occupations at an increased risk of suicide due to the large proportion of occupations that were not specified. However, it is unlikely that systematic misclassification bias would have affected deaths by suicide. A further consideration was that we did not adjust or correct for the wrong assignment or ill-defined causes of death. In the study period, $11.6 \%(1,196,031)$ of deaths were assigned as ill-defined or unknown causes of death (R99). Redistribution of ill-defined causes may result in more reliable estimates of suicide mortality rates.

\section{Conclusions}

Suicide mortality and method of suicide vary by sex and between age groups in the South African population across 20 years. Completeness of death registration data is necessary for accurate calculation of mortality rates. While the quality of death registration data has improved $[14,54]$, ongoing training is needed on death certification skills. Efforts to improve our understanding of the epidemiology of suicide should continue in order to reduce the morbidity and mortality associated with suicide. Surveillance of vital registry data is a critical epidemiological tool for evaluating the effectiveness of health services and current mental health policies and can inform targeted prevention strategies for those at increased risk of suicide in South Africa.

Author Contributions: Conceptualization, T.K. and N.N.; methodology, T.K.; formal analysis, T.K.; writing-original draft preparation, T.K.; writing-review and editing, N.N.; K.S.W., R.R., and L.L.; supervision, L.L. and R.R. All authors have read and agreed to the published version of the manuscript.

Funding: This work was supported by the South African Medical Research Council through its Division of Research Capacity Development under the Clinician Researcher Development PhD Scholarship Programme. The content hereof is the sole responsibility of the author and does not necessarily represent the official views of the SAMRC.

Conflicts of Interest: The authors declare no conflict of interest. The funders had no role in the design of the study; in the collection, analyses, or interpretation of data; in the writing of the manuscript, or in the decision to publish the results. 


\section{References}

1. Naghavi, M. Global, regional, and national burden of suicide mortality 1990 to 2016: Systematic analysis for the Global Burden of Disease Study 2016. Br. Med J. 2019, 364, 194. [CrossRef] [PubMed]

2. WHO. Preventing Suicide: A Global Imperative; World Health Organisation: Geneva, Switzerland, 2014; Available online: http://www.who.int/mental_health/suicid-eprevention/world_report_2014/en/ (accessed on 1 September 2019).

3. van Heeringen, K. Stress-Diathesis Model of Suicidal Behavior. In The Neurobiological Basis of Suicide; Dwivedi, Y., Ed.; CRC Press/Taylor \& Francis: Boca Raton, FL, USA, 2012.

4. Bertolote, J.M. Suicide in the world: An epidemiological overview 1959-2000. In Suicide: An Unnecessary Death; Wasserman, D., Ed.; Martin Dunitz: London, UK, 2001; pp. 3-10.

5. Mars, B.; Burrows, S.; Hjelmeland, H.; Gunnell, D. Suicidal behaviour across the African continent: A review of the literature. BMC Public Health 2014, 14, 606. [CrossRef]

6. Matzopoulos, R.; Prinsloo, M.; Pillay-van Wyk, V.; Gwebushe, N.; Mathews, S.; Martin, L.J.; Laubscher, R.; Abrahmas, N.; Msemburi, W.; Lombard, C.; et al. Injury-related mortality in South Africa: A retrospective descriptive study of postmortem investigations. Bull. World Health Organ. 2015, 93, 303-313. [CrossRef] [PubMed]

7. Burrows, S.; Laflamme, L. Suicide mortality in South Africa. Soc. Psychiatry Psychiatr. Epidemiol. 2006, 41, 108-114. [CrossRef] [PubMed]

8. Bertolote, J.M.; Fleischmann, A. A global perspective in the epidemiology of suicide. Suicidologi 2002, 7, 6-8. [CrossRef]

9. Ajdacic-Gross, V.; Weiss, M.G.; Ring, M.; Hepp, U.; Bopp, M.; Gutzwiller, F.; Rossler, W. Methods of suicide: International suicide patterns derived from the WHO mortality database. Bull. World Health Organ. 2008, 86, 726-732. [CrossRef]

10. Meltzer, H.; Griffiths, C.; Brock, A.; Rooney, C.; Jenkins, R. Patterns of suicide by occupation in England and Wales: 2001-2005. Br. J. Psychiatry 2008, 193, 73-76. [CrossRef]

11. Scribante, L.; Blumenthal, R.; Saayman, G.; Roos, J.L. A retrospective review of 1018 suicide cases from the capital city of South Africa for the period 1997-2000. Am. J. Forensic Med. Pathol. 2004, 25, 52-55. [CrossRef]

12. Stark, K.; Joubert, G.; Struwig, M.; Pretorius, M.; Van der Merwe, N.; Botha, H.; Kotzé, J.; Krynauw, D. Suicide cases investigated at the state mortuary in Bloemfontein, 2003-2007. S. Afr. Fam. Pract. 2010, 52, 332-335. [CrossRef]

13. Lopez, A.D.; AbouZahr, C.; Shibuya, K.; Gollogly, L. Keeping count: Births, deaths, and causes of death. Lancet 2007, 370, 1744-1746. [CrossRef]

14. Mathers, C.D.; Ma Fat, D.; Inoue, M.; Rao, C.; Lopez, A.D. Counting the dead and what they died from: An assessment of the global status of cause of death data. Bull. World Health Organ. 2005, 83, 171c-177c.

15. Joubert, J.; Rao, C.; Bradshaw, D.; Vos, T.; Lopez, A.D. Evaluating the quality of national mortality statistics from civil registration in South Africa, 1997-2007. PLoS ONE 2013, 8, e64592. [CrossRef] [PubMed]

16. Statistics South Africa Datasets. Mortality and Causes of Death 1997-2016. Available online: http: //nesstar.statssa.gov.za:8282/webview/ (accessed on 1 September 2019).

17. Statistics South Africa. South African Standard Classification of Occupations (SASCO). Pretoria Statistics South Africa. Available online: http://www.statssa.gov.za/classifications/codelists/SASCO_2012.pdf (accessed on 1 September 2019).

18. Ahmad, O.B.; Boschi-Pinto, C.; Lopez, A.D.; Murray, C.J.; Lozano, R.; Inoue, M. Age standardization of rates: A new WHO standard. Geneva World Health Organ. 2001, 31, 1-14.

19. Gardner, J.W.; Sanborn, J.S. Years of potential life lost (YPLL)—What does it measure? Epidemiology 1990, 1, 322-329. [CrossRef] [PubMed]

20. Cleophas, T.J.; Zwinderman, A.H. Spline Regression Modeling. In Regression Analysis in Medical Research; Springer: Berlin, Germany, 2018; pp. 267-277.

21. Kim, H.J.; Fay, M.P.; Feuer, E.J.; Midthune, D.N. Permutation tests for joinpoint regression with applications to cancer rates. Stat. Med. 2000, 19, 335-351. [CrossRef]

22. JoinPoint Regression Program Version 4.0.4. Surveillance Research Program: Statistical Research and Applications Branch, National Cancer Institute; National Cancer Institute: Bethesda, MD, USA, 2013. 
23. Lerman, P. Fitting segmented regression models by grid search. J. R. Stat. Soc. Ser. C (Appl. Stat.) 1980, 29, 77-84. [CrossRef]

24. Flisher, A.J.; Liang, H.; Laubscher, R.; Lombard, C.F. Suicide trends in South Africa, 1968-1990. Scand. J. Public Health 2004, 32, 411-418. [CrossRef]

25. Vijayakumar, L. Suicide in women. Indian J. Psychiatry 2015, 57 (Suppl. S2), S233. [CrossRef]

26. Phillips, M.R.; Li, X.; Zhang, Y. Suicide rates in China, 1995-1999. Lancet 2002, 359, 835-840. [CrossRef]

27. Park, S.; Ahn, M.H.; Lee, A.; Hong, J.P. Associations between changes in the pattern of suicide methods and rates in Korea, the, U.S.; and Finland. Int. J. Ment. Health Syst. 2014, 8, 22. [CrossRef]

28. Puzo, Q.; Qin, P.; Mehlum, L. Long-term trends of suicide by choice of method in Norway: A joinpoint regression analysis of data from 1969 to 2012. BMC Public Health 2016, 16, 255. [CrossRef] [PubMed]

29. Daigle, M.S. Suicide prevention through means restriction: Assessing the risk of substitution: A critical review and synthesis. Accid. Anal. Prev. 2005, 37, 625-632. [CrossRef] [PubMed]

30. Denning, D.G.; Conwell, Y.; King, D.; Cox, C. Method choice, intent, and gender in completed suicide. Suicide Life-Threat. Behav. 2000, 30, 282-288. [PubMed]

31. Gunnell, D.; Bennewith, O.; Hawton, K.; Simkin, S.; Kapur, N. The epidemiology and prevention of suicide by hanging: A systematic review. Int. J. Epidemiol. 2005, 34, 433-442. [CrossRef] [PubMed]

32. Biddle, L.; Donovan, J.; Owen-Smith, A.; Potokar, J.; Longson, D.; Hawton, K.; Kapur, N.; Gunnell, D. Factors influencing the decision to use hanging as a method of suicide: Qualitative study. Br. J. Psychiatry 2010, 197, 320-325. [CrossRef] [PubMed]

33. Eddleston, M. Patterns and problems of deliberate self-poisoning in the developing world. QJM Int. J. Med. 2000, 93, 715-731. [CrossRef]

34. Veale, D.J.H.; Wium, C.A.; Müller, G.J. Toxicovigilance I: A survey of acute poisonings in South Africa based on Tygerberg Poison Information Centre data. S. Afr. Med. J. 2013, 103, 293-297. [CrossRef]

35. Bertolote, J.M.; Fleischmann, A.; Eddleston, M.; Gunnell, D. Deaths from Pesticide Poisoning: Are we lacking a global response? Br. J. Psychiatry 2006, 189, 201-203. [CrossRef]

36. Shibre, T.; Hanlon, C.; Medhin, G.; Alem, A.; Kebede, D.; Teferra, S.; Kullgren, G.; Jacobsson, L.; Fekadu, A. Suicide and suicide attempts in people with severe mental disorders in Butajira, Ethiopia: 10 year follow-up of a population-based cohort. BMC Psychiatry 2014, 14, 150. [CrossRef]

37. Kinyanda, E.; Wamala, D.; Musisi, S.; Hjelmeland, H. Suicide in urban Kampala, Uganda: A preliminary exploration. Afr. Health Sci. 2011, 11, 219-227.

38. Patience, M. Retrospective Analysis of Suspected Pesticide-Related Fatalities Admitted to Salt River Mortuary in the West Metropole of Cape Town; University of Cape Town: Cape Town, South Africa, 2018.

39. Mahon, M.J.; Tobin, J.P.; Cusack, D.A.; Kelleher, C.; Malone, K.M. Suicide among regular-duty military personnel: A retrospective case-control study of occupation-specific risk factors for workplace suicide. Am. J. Psychiatry 2005, 162, 1688-1696. [CrossRef] [PubMed]

40. London, L.; Flischer, A.J.; Wesseling, C.; Mergler, D.; Kromhout, H. Suicide and exposure to organophosphate insecticides: Cause or effect? Am. J. Ind. Med. 2005, 47, 308-321. [CrossRef] [PubMed]

41. Hawton, K.; Fagg, J.; Simkin, S.; Harriss, L.; Malmberg, A.; Smith, D. The geographical distribution of suicides in farmers in England and Wales. Soc. Psychiatry Psychiatr. Epidemiol. 1999, 34, 122-127. [CrossRef] [PubMed]

42. Iemmi, V.; Bantjes, J.; Coast, E.; Channer, K.; Leone, T.; McDaid, D.; Palfreyman, A.; Stephens, B.; Lund, C. Suicide and poverty in low-income and middle-income countries: A systematic review. Lancet Psychiatry 2016, 3, 774-783. [CrossRef]

43. Blakely, T.A.; Collings, S.C.; Atkinson, J. Unemployment and suicide. Evidence for a causal association? J. Epidemiol. Community Health 2003, 57, 594-600. [CrossRef]

44. Nordt, C.; Warnke, I.; Seifritz, E.; Kawohl, W. Modelling suicide and unemployment: A longitudinal analysis covering 63 countries, 2000-2011. Lancet Psychiatry 2015, 2, 239-245. [CrossRef]

45. WHO. Global Health Estimates 2015: Deaths by Cause, Age, Sex, by Country and by Region, 2000-2015. Geneva World Health Organ. 2016. Available online: https://www.who.int/gho/mortality_burden_disease/ mortality_adult/situation_trends/en/ (accessed on 2 February 2020).

46. Rehkopf, D.H.; Buka, S.L. The association between suicide and the socio-economic characteristics of geographical areas: A systematic review. Psychol. Med. 2006, 36, 145-157. [CrossRef] 
47. Grigoriev, P.; Doblhammer-Reiter, G.; Shkolnikov, V. Trends, patterns, and determinants of regional mortality in Belarus, 1990-2007. Popul. Stud. 2013, 67, 61-81. [CrossRef]

48. Khan, M.M.; Mahmud, S.; Karim, M.S.; Zaman, M.; Prince, M. Case-control study of suicide in Karachi, Pakistan. Br. J. Psychiatry 2008, 193, 402-405. [CrossRef]

49. Gururaj, G.; Isaac, M.; Subbakrishna, D.; Ranjani, R. Risk factors for completed suicides: A case-control study from Bangalore, India. Inj. Control. Saf. Promot. 2004, 11, 183-191. [CrossRef]

50. Knipe, D.W.; Carroll, R.; Thomas, K.H.; Pease, A.; Gunnell, D.; Metcalfe, C. Association of socio-economic position and suicide/attempted suicide in low and middle income countries in South and South-East Asia -A systematic review. BMC Public Health 2015, 15, 1055. [CrossRef] [PubMed]

51. Pompili, M.; Vichi, M.; Qin, P.; Innamorati, M.; De Leo, D.; Girardi, P. Does the level of education influence completed suicide? A nationwide register study. J. Affect. Disord. 2013, 147, 437-440. [CrossRef] [PubMed]

52. Devries, K.; Watts, C.; Yoshihama, M.; Kiss, L.; Schraiber, L.B.; Deyessa, N.; Heise, L.; Durand, J.; Mbwambo, J.; Jansen, H.; et al. Violence against women is strongly associated with suicide attempts: Evidence from the WHO multi-country study on women's health and domestic violence against women. Soc. Sci. Med. 2011, 73, 79-86. [CrossRef]

53. Flisher, A.J.; Parry, C.D.; Bradshaw, D.; Juritz, J.M. Seasonal variation of suicide in South Africa. Psychiatry Res. 1997, 66, 13-22. [CrossRef]

54. Burrows, S.; Laflamme, L. Assessment of accuracy of suicide mortality surveillance data in South Africa: Investigation in an urban setting. Crisis 2007, 28, 74-81. [CrossRef] [PubMed]

(C) 2020 by the authors. Licensee MDPI, Basel, Switzerland. This article is an open access article distributed under the terms and conditions of the Creative Commons Attribution (CC BY) license (http://creativecommons.org/licenses/by/4.0/). 